\title{
Effect of an educational program for farming mothers to protect their children from pesticide exposure
}

\author{
M Amal ${ }^{1}, \mathrm{M} \mathrm{Nahed}^{2}, \mathrm{~S} \mathrm{Soad}^{3}$ \\ $\left({ }^{1,2}\right.$ Lecturer of Pediatric Nursing-Faculty of Nursing, Assiut University, Egypt $)$ \\ $\left({ }^{3}\right.$ Assistance professor of Community Health Nursing- Faculty of Nursing, Assiut University, Egypt)
}

\begin{abstract}
Pesticides represent a major environmental hazard. The toxic effects of pesticides are a concern among high risk groups, especially children.

Aim: To evaluate the effect of an educational program for farming mothers to protect their children from pesticide exposure.

Subjects and method: Quiz-experimental design was used for this study. The study was conducted in general pediatric out- patient clinics at Assuit University Children Hospital. The study subjects included a convenient sample of 60 farming mothers. Two tools were developed by the researchers for data collection. Tool I: Socioeconomic scale; it was developed by (Abd El-Twaab 2004). Tool II: Structure interview questionnaire: divided into two parts: Part 1 Questions to assess farming mothers' knowledge about pesticides: Part 11: Questions to assess farming mothers' knowledge about their practice regarding pesticides.

Results: the mean age of the mothers was $38.8 \pm 9.7$ years. $60 \%$ were illiterate, $95 \%$ were house wife and farmer, and more than half were in the middle social class. Most of the mothers had poor knowledge and unsatisfactory knowledge about practices in the pretest. Statistically significant differences were detected between mothers' total score of knowledge and their knowledge about practice.

Conclusions: Most of the mothers had poor level of knowledge and unsatisfactory knowledge about practice regarding pesticide in preprogram and after implementation of program, the level of mothers 'knowledge and their knowledge about practice improved.

Recommendation: Medical conveys in the village for the public about pesticides by the directors of rural health units shared with professors in medicine and nursing in the university. Using mass media to disseminate correct information about pesticides and to increasing the mothers' awareness about its harmful effect on health.
\end{abstract}

Keywords: pesticides, farming mothers, knowledge, practices,

\section{Introduction}

Pesticides are substances meant for preventing, destroying or mitigating any pest. The most common use of pesticides is as plant protection products, which in general protect plants from damaging influences such as weeds, diseases or insects. The pesticides which used in the home and garden such as slug pellets, weed killers and ant powders, as well as those used by farmers. In addition to long workdays, injuries, and fatalities associated with agricultural work, pesticides pose a particularly serious threat to people living or working in the field [1].

According to the Stockholm Convention on Persistent Organic Pollutants, 9 of the 12 most dangerous and persistent organic chemicals are pesticides [1]. More than an estimated billion pounds of active pesticide ingredients are used annually in the United States, representing approximately one quarter of worldwide pesticide use [2].

Pesticide poisoning has been recognized as an important public health issue around the world. Approximately 350,000-440,000 annual suicides by means of deliberate pesticide poisoning have been estimated to occur worldwide [3]. The numbers of victims of nonfatal pesticide poisoning are assumed to be much greater [4]. Pesticides are widely used in agriculture in Egypt. Approximately 10. 000 to 60.000 tons of pesticides are used annually in agriculture or for public health reasons [5].

Agriculture is a workplace unlike many others in our country. Farm families often live practically in the middle of the work environment and help out on the job. As a result, children can come into close contact with dangerous pesticides. Residues from the parents' clothing, dust tracked into the house, contaminated soil, food brought directly from the fields to the table, and contaminated water are significant sources of exposure for farm children. Children are particularly vulnerable to pesticide exposure because of immature biological and developmental processes [6]. So it is important to pay attention to their exposures and their health because of what they can tell us about risks to all children [7].

Large families, small accommodation, carless storage of potentially poisonous household substance, easy availability of poisons, lack of time for supervision of children, lack of discipline and anticipatory guidance 
are influencing factors of greater risk of poisoning [8]. Pesticides can enter the body orally, dermally or by inhalation. Clothing contaminated with pesticides can be an important route of exposure for children [9].

The signs and symptoms of pesticide poisoning depend upon the pesticide involved and the type and magnitude of exposure. Mild signs of acute pesticide poisoning, such as nausea, vomiting, diarrhea, or wheezing are often not recognized as being potentially linked to pesticide toxicity. Rashes and other skin reactions are another major manifestation of pesticide toxicity that is often misdiagnosed [10].

Chronic effects of pesticide exposure may include adverse effects on neurological function, cancer, reproductive harm, reduced growth and development, and birth defects. Much of the evidence of chronic effects is based on studies of adult workers who are exposed to a mixture of chemicals every day, making it difficult to pinpoint specific pesticides. Little research on the chronic effects of pesticides has been done directly on children, and even less on farm children[11].

The diagnosis is based upon the history of exposure, such as pesticides are available in the home, recently applied, or child was found playing with containers. Also signs and symptoms of exposure and laboratory measurements. After acute exposures, pesticides and their metabolites can be measured in samples of blood, urine, breast milk, amniotic fluid or meconium. This can confirm the diagnosis [12].

Specific treatments for acute pesticide poisoning are often dependent on the pesticide or class of pesticide responsible for the poisoning. However, there are basic management techniques that are applicable to most acute poisonings, including; skin decontamination, air way protection, gastrointestinal decontamination, and seizure treatment [11].

Pesticides should be used only when the benefits outweigh the risks, and non-chemical pest control procedures have failed. Integrated pest management (IPM) procedures which include hygiene, sealing of cracks and crevices, screening of doors and windows, and other measures should be the first line of defense for pest management. If pesticides must be used, they should be stored only in their original containers with manufacturers' labels intact, preferably with child-proof seals, out of the reach of children and in locked cabinets or cupboards. Users should always follow the safety precautions specified by the manufacturer and observe all safety recommendations including use of gloves, masks, protective clothing and observation of reentry times [13].

Pesticide safety education and pesticide applicator regulation are designed to protect the public from pesticide misuse, but do not eliminate all misuse. Reducing the use of pesticides and choosing less toxic pesticides may reduce risks placed on society and the environment from pesticide use [4].The pediatric nurse play a unique role in pesticide poisoning prevention because of their regular contact with patients, care givers and the general public [14]. Arrange for counseling of parents, children and guide the parents for regular psychological follow up. Teach the parents and family members about the prevention of accidental poisoning and need for parental supervision [8].

\section{Significance of the study:}

Poisoning is one of the important accidental hazards among children. The children below five years of age are the common victim of this problem [8]. Pesticides represent a major environmental hazard. The toxic effects of pesticides are a concern among high-risk groups, especially children [5]. Therefore development of culturally educational programs for farming mothers about pesticide is essential to protect their children from hazard of pesticides exposure.

\section{Aims of the work:}

This study aimed to

- To assess the farming mothers' knowledge and their knowledge about practice regarding pesticides.

- To evaluate the effect of an educational program for farming mothers about pesticides

\subsection{Hypothesis of the study}

\section{Subjects and Method}

Lack of farming mother's knowledge and unsatisfactory knowledge about practice regarding pesticides.

\subsection{Research Design:}

Quiz - experimental study was used

2.3 Setting:

The study was conducted at general pediatric out-patient clinics at Assuit University Children Hospital 2.4 Subjects:

The study subjects included a convenient sample of 60 farming mothers

2.5 Tools of the study:

Two tools were utilized for this study: 
Effect of an educational program for farming mothers to protect their children from pesticide..

Tool I: Socioeconomic scale; it was developed by [15] and used to assess the socioeconomic status. It included four items; level of education of parents ( 8 items), family income (6 items), job of parent ( 2 items), and life styles (3 items). Each item have one score the total score was divided into three classes as high, moderate and low classes. The item of income has been modified of social class by the researchers as following; according to the rate of inflation and increase to be conforming to recent income. Each item have one score; as high from 85 $100 \%$, moderate from $60-84 \%$ and low less than $60 \%$.

Tool II: Structure interview questionnaire divided into two parts.

Part 1: Questions to assess farming mothers knowledge: which include definition of pesticides and period of prohibition, types, methods of transmission, effect on children's health, family past history about exposure of children to pesticides such as; frequency of using pesticides inside the house, types of pesticides causing poisoning, child complains and place of first aid and sources of information for farming mothers

Part 11: Questions to assess farming mothers knowledge about their practice regarding precautions to be followed; before, during, after and at storing of pesticides. Precautions to prevent children's from pesticides exposure at home and agriculture. The protective methods used by the mothers and the alternative methods used to reduce the using of pesticides at home and agriculture.

The content validity of the program and tools were assessed by a jury of 5 experts in the pediatrics and pediatric nursing field the content validity index was 95\%. Reliability was assessed using Cronbach $\alpha$ test to measure the internal consistency and its result was $\mathrm{R}=0.66$.

\subsection{Pilot study}

Before embarking on the actual study, a pilot study was carried out on $10 \%$ of the sample to assess the tools for clarity, reliability and applicability and to evaluate the time needed for filling the sheet. The necessary modifications were done based on the results of the pilot study and these farming mothers were excluded from the study subjects.

\subsection{Methods of data collection: \\ 2.7.1 Preparation phase}

Before implementation of the study, an official permission was obtained from Dean of the Faculty of Nursing directed to the director of out-patient clinics for data collection after explaining the purpose of the study. Approval of nursing ethical committee in the faculty was obtained.

The program has been specially designed for farming mothers in Arabic language thorough review of the upto- date literature relevant to the study subject was done prior to the development of an interview questionnaire.

\subsubsection{Planning phase}

General and specific objectives were developed and explained for mothers prior implementation of the program.

\subsubsection{Strategy}

Discussions through booklet contained colored pictures, posters, and power point were used as a method to teach the farming mothers.

\subsubsection{Implementation}

The data were collected starting from October 2015 to the end of the March 2016. The researchers interviewed the mothers and their children in Out-Patient Clinics coming from rural areas, at Assuit University Children Hospital. Data was collected before the application of the program and after 3 weeks from the program application. During interview the researchers introduce them self to the mothers and their children to explain the purpose and nature of the study. The theoretical part of the program presented in two day, the researchers did the interview with the mothers throughout three sessions one session began to fill the interview sheet and applied the pretest and giving handout before starting the session of the program. The second session for explaining the program and the second day for doing posttest. The researchers interviewed on three to five mothers one day/weekly. The average time for filing the pretest sheet was around 10-15 minutes depending on the response of farming mothers. After that the program content was discussed through booklet contained colored pictures, posters, and power point at students teaching class. The average time to applied and filing the posttest sheet was around 20-30 minutes.

2.7.5 Evaluation of the program was completed by using the (pre and posttest). This evaluation based on scoring system as following: 
Effect of an educational program for farming mothers to protect their children from pesticide..

1- Scoring system for knowledge. It consisted of 9 questions were used for farming mothers, each complete correct answer takes two score, incomplete correct answer takes one score and incorrect answer takes zero score. The grading of farming mothers according to their knowledge total score was interpreted as the following: poor $=\langle 50 \%$, good $50 \%: 70 \%$ and very good $=>70 \%[16]$.

2- Scoring for assess mothers knowledge about their practice. It consisted of (7 Questions) with 56 right answer. The score that was given for subject to responses was zero for unsatisfactory, one for satisfactory. The grading of farming mothers according to their practice total score was interpreted as the following: unsatisfactory (less than 75\%) and satisfactory (75\% and more) [17].

\subsection{Ethical consideration}

The researchers were explained to farming mother and their children the aim of the study and confidentiality of the data. They were informed about their right to withdraw from the study at any point. Finally there is no risk for farming mothers/or their children at all during application of the research.

\subsection{Analysis of Data}

The data analyses were performed with the IBM SPSS 20.0 software. Categorical variables were described by number and percent $(\mathrm{N}, \%)$, where continuous variables described by mean and standard deviation (Mean, SD).Continues variables test for normality using Anderson Darling . Chi-square test and fisher exact test used to compare between categorical variables where. Paired $\mathrm{T}$ test used to compare between continuous variables. Pearson correlation coefficient was done to measure correlation between quantitative variables. Pvalue considered statistically significant when $\mathrm{P}<0.05$.

\section{Results}

Table (1): Sociodemographic characteristics of the studied farming mothers

\begin{tabular}{|c|c|c|}
\hline Items & No. $(n=60)$ & $\%$ \\
\hline Mother Age: years & & \\
\hline$<25$ years & 3 & 5.0 \\
\hline $25-35$ years & 14 & 23.3 \\
\hline$\geq 35$ years & 43 & 71.7 \\
\hline Mean \pm SD & \multicolumn{2}{|c|}{$38.8+9.7$} \\
\hline Mother education: & & \\
\hline Illiterate & 36 & 60.0 \\
\hline Basic education & 17 & 28.3 \\
\hline Secondary & 7 & 11.7 \\
\hline \multicolumn{3}{|l|}{ Mother occupation: } \\
\hline House wife and farmer & 57 & 95.0 \\
\hline Employee & 3 & 5.0 \\
\hline \multicolumn{3}{|l|}{ Marital status: } \\
\hline Mired & 5 & 8.3 \\
\hline Divorced & 19 & 31.7 \\
\hline Widow & 36 & 60.0 \\
\hline \multicolumn{3}{|l|}{ Family size: } \\
\hline $4-8$ person & 38 & 63.3 \\
\hline$\geq 8$ & 22 & 36.7 \\
\hline Mean+SD & \multicolumn{2}{|c|}{$6.8+1.7$} \\
\hline \multicolumn{3}{|l|}{ Social class: } \\
\hline Low & 8 & 13.3 \\
\hline Middle & 35 & 58.3 \\
\hline High & 17 & 28.3 \\
\hline
\end{tabular}

Table (1): represented that ,less than three quarters (71.7\%) of the farming mothers age were 35 years and more, with mean age 38.8 \pm 9.7 years .less than two thirds $(60 \%)$ were illiterate and widow. Moreover the vast majority of them (95\%) were house wife and farmer. Regarding family size about two third $(63.3 \%)$ had family size from $4-8$ person, with mean of $6.8 \pm 1.7$. Finally more than half $(58.3 \%)$ of farming mothers had middle social class.

Table (2): Family history regarding exposure of children to pesticides

\begin{tabular}{|c|c|c|}
\hline Family history & $\begin{array}{c}\text { No. } \\
(\mathbf{n = 6 0})\end{array}$ & $\%$ \\
\hline Children exposed to poisoning by pesticides: & 8 & \\
\hline Yes & 52 & 13.3 \\
\hline No & 86.7 \\
\hline
\end{tabular}


Effect of an educational program for farming mothers to protect their children from pesticide..

\begin{tabular}{|c|c|c|}
\hline Frequency of exposure to poisoning $\mathbf{: n = 8}$ & & \\
\hline Once & 8 & 13.3 \\
\hline Frequency of using pesticides inside the home: & & \\
\hline every day & 2 & 3.3 \\
\hline every two days & 4 & 6.7 \\
\hline Every three days & 9 & 15.0 \\
\hline Every four days and more & 45 & 75.0 \\
\hline Types of pesticides causing poisoning: $\mathbf{n = 8}$ & & \\
\hline Home pesticides & 4 & 50.0 \\
\hline Farming pesticides & 4 & 50.0 \\
\hline Child complains $\mathbf{n}=\mathbf{8}$ & & \\
\hline Gastrointestinal disturbance & 2 & 25.0 \\
\hline Chest disturbance & 2 & 25.0 \\
\hline Gastrointestinal and Chest disturbance & 4 & 50.0 \\
\hline Place of first aid: $\mathbf{n}=\mathbf{8}$ & & \\
\hline Hospital & 4 & 50.0 \\
\hline Health care unit & 4 & 50.0 \\
\hline
\end{tabular}

Table (2): shows that, the minority of mothers (13.3\%) said their children exposed to poisoning by pesticide and exposed only once. Three quarter of the farming mothers $(75.0 \%)$ used pesticides inside the home every four days and more weekly. Half of the children poisoned from home pesticides and the same percentage from farming pesticide. As regards to child complains half of them had complained from gastrointestinal tract and chest disturbance, also the same percentage received the first aid in the hospital and health care unit (50\%).

Table (3): Percentage distribution of farming mothers' knowledge about pesticides in pre and post program

\begin{tabular}{|l|l|l|l|l|}
\hline \multirow{2}{*}{ Mothers knowledge } & Pre test & Post test & No. $(\mathbf{n}=\mathbf{6 0})$ & \% \\
\cline { 2 - 5 } & No. $(\mathbf{n}=\mathbf{6 0})$ & $\mathbf{\%}$ & & \\
\hline Definition of pesticides: & & & 6 & 10.0 \\
\hline Correct complete answer & 2 & 3.3 & 50 & 83.3 \\
\hline Correct incomplete answer & 33 & 55.0 & & 6.7 \\
\hline Incorrect answer & 25 & 41.7 & 4 & \\
\hline Definition period of prohibition: & & & & 56.7 \\
\hline Correct complete answer & 4 & 6.7 & 34 & 36.7 \\
\hline Correct incomplete answer & 14 & 23.3 & 22 & 6.6 \\
\hline Incorrect answer & 42 & 70.0 & 4 & \\
\hline Types of pesticides used in the home:\# & & & & 96.7 \\
\hline Peirsol to kill flying insects & 54 & 90.0 & 58 & 95.0 \\
\hline powder for cockroaches crawling & 38 & 63.3 & 57 & 90.0 \\
\hline pesticide for mouse & 39 & 65.0 & 54 & 38.3 \\
\hline powder or liquid to kill the head lice & 8 & 13.3 & 23 & \\
\hline Methods of transmission:\# & & & & 100.0 \\
\hline By inhalation & 59 & 98.3 & 60 & 65.0 \\
\hline Through ingestion / swallowing with digestion & 18 & 30.0 & 39 & 70.0 \\
\hline Through the skin & 26 & 41.7 & 42 & 73.3 \\
\hline Through the eye & 19 & 31.7 & 44 & \\
\hline Effect of pesticides on children's health:\# & & & & 100.0 \\
\hline The sensitivity of the chest & 57 & 95.0 & 60 & 58 \\
\hline The sensitivity of the skin & 0 & 0.0 & 47 & 15.0 \\
\hline Toxic effect on the liver & 9 & 15.0 & 9 & 16.7 \\
\hline Reducing child's memory & 10 & 16.7 & 10 & 56.7 \\
\hline Reducing the child's intelligence & 1 & 1.7 & 34 & 68.3 \\
\hline Its effects on the nervous system & 14 & 23.3 & 41 & \\
\hline
\end{tabular}

\section{More than one answers \#}

Table (3): shows that, more than half (55\%) of studied mothers gave correct incomplete answer about definition of pesticides in pretest compared to $(83.3 \%)$ in posttest .Also less than three quarters of them (70\%) gave incorrect answer related to definition of period of prohibition before the program compared to (6.6\%) in posttest .As regards to types of pesticides used in the home $(90 \%)$ and $(96.7 \%)$ of the farming mothers mentioned peirsol to kill flying insects in pretest and posttest respectively. The vast majority of them (98.3\%) mentioned the pesticides enter the body through inhalation in pretest compared to $(100 \%)$ in posttest. The majority of the mothers (95\%) mentioned sensitivity of the chest and only $1.7 \%$ mentioned reducing the child intelligence as effect of pesticides on the child health in pretest compared to $100 \%$ and $56.7 \%$ in posttest. 


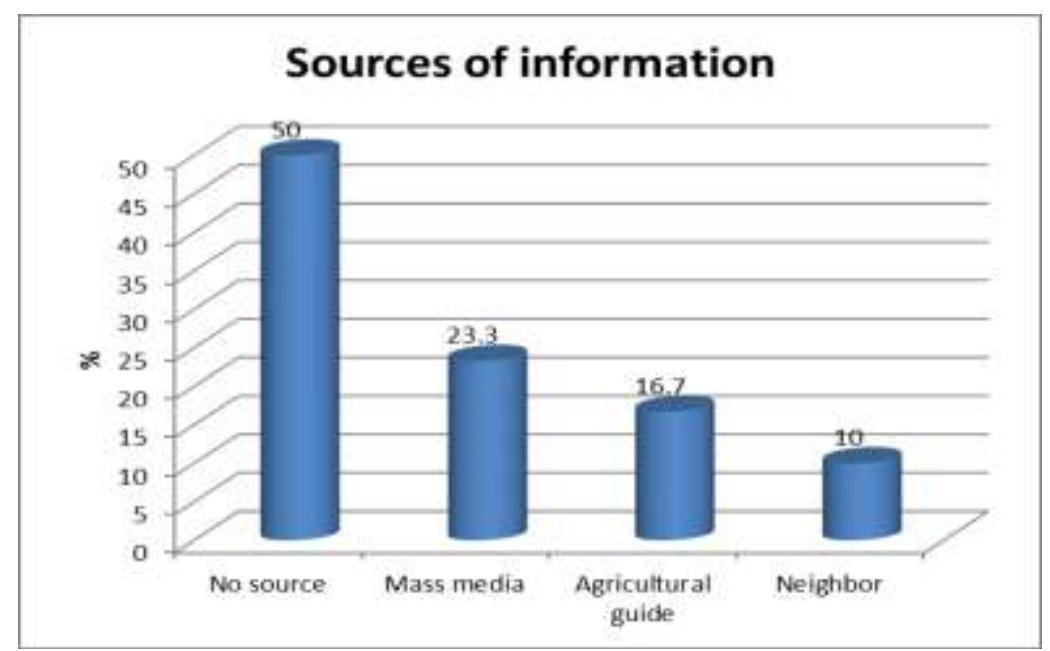

Fig (1): Frequency distribution of farming mothers regarding the sources of information about pesticides.

Figure (1): this figure shows that, half of the mothers don't had any source of information about pesticides, while the information from mass media, agricultural guide and neighbor were constituted $23.3 \%, 16.7 \%$ and $10 \%$ respectively.

Table (4): Percentage distribution of farming mother's knowledge about their practice regarding pesticides in pre and posttest program.

\begin{tabular}{|c|c|c|c|c|c|c|c|c|c|}
\hline \multirow[t]{3}{*}{ Mothers practice } & \multicolumn{4}{|c|}{ Pretest program } & \multicolumn{4}{|c|}{ Posttest program } & \multirow{3}{*}{ P. value } \\
\hline & \multicolumn{2}{|c|}{ Satisfactory } & \multicolumn{2}{|c|}{ Unsatisfactory } & \multicolumn{2}{|c|}{ Satisfactory } & \multicolumn{2}{|c|}{ Unsatisfactory } & \\
\hline & No. & $\%$ & No. & $\%$ & No. & $\%$ & No. & $\%$ & \\
\hline \multicolumn{10}{|l|}{ 1-Precautions to be followed:\# } \\
\hline a-Before using pesticides. & 10 & 16.7 & 50 & 83.3 & 48 & 80.0 & 12 & 20.0 & $<0.001 * *$ \\
\hline b- During using pesticides. & 23 & 38.3 & 37 & 61.7 & 50 & 83.3 & 10 & 16.7 & $<0.001 * *$ \\
\hline c- After using pesticides. & 14 & 23.3 & 46 & 76.7 & 54 & 90.0 & 6 & 10.0 & $<0.001 * *$ \\
\hline d-Storing pesticides at home. & 18 & 30.0 & 42 & 30.0 & 52 & 86.7 & 8 & 13.3 & $<0.001 * *$ \\
\hline \multicolumn{10}{|c|}{ 2-Precautions to prevent children from pesticides exposure:\# } \\
\hline a-At home. & 27 & 45.0 & 33 & 55.0 & 51 & 85.0 & 9 & 15.0 & 0.079 \\
\hline b- At agriculture. & 25 & 41.7 & 35 & 58.3 & 49 & 81.7 & 11 & 18.3 & $<0.001 * *$ \\
\hline 3- Using the protective methods. & 2 & 3.3 & 58 & 96.7 & 34 & 56.7 & 26 & 43.3 & $<0.001 * *$ \\
\hline \multicolumn{10}{|c|}{ 4-The alternative methods used to reduce using pesticides:\# } \\
\hline a-At home. & 2 & 3.3 & 58 & 96.7 & 54 & 90.0 & 6 & 10.0 & 0.143 \\
\hline b-At agriculture. & 1 & 1.7 & 59 & 98.3 & 31 & 51.7 & 29 & 48.3 & $<0.001 * *$ \\
\hline
\end{tabular}

\section{More than one answer\#}

Table (4): illustrated that, a statistically significant differences were detected between farming mothers' knowledge about their practice in pre and posttest related to all variables $\mathrm{p}=0.001$,except for precautions to prevent children from pesticides exposure and the alternative methods used to reduce the using pesticides at home.

Table (5): Relationship between the farming mothers' total score of knowledge and their total score of knowledge about practice regarding pesticides.

\begin{tabular}{|c|c|c|c|c|c|c|c|c|c|c|}
\hline \multirow{4}{*}{ Items } & \multicolumn{10}{|c|}{ Total score of knowledge } \\
\hline & \multicolumn{4}{|c|}{ Pretest } & \multirow{3}{*}{ P. value } & \multicolumn{4}{|c|}{ Posttest } & \multirow{3}{*}{ P. value } \\
\hline & \multicolumn{2}{|c|}{ Good } & \multicolumn{2}{|c|}{ Poor } & & \multicolumn{2}{|c|}{ Good } & \multicolumn{2}{|c|}{ Poor } & \\
\hline & No. & $\%$ & No. & $\%$ & & No. & $\%$ & No. & $\%$ & \\
\hline Total score of Practice: & & & & & & & & & & \\
\hline Satisfactory & 1 & 1.7 & 13 & 21.6 & & 37 & 61.7 & 10 & 16.7 & \\
\hline Unsatisfactory & 1 & 1.7 & 45 & 75.0 & 0.364 & 2 & 3.3 & 11 & 18.3 & $<0.001^{* *}$ \\
\hline
\end{tabular}

Table (5): reveled that, there were significant relation between the farming mothers' total score of knowledge and their total score of knowledge about practice regarding pesticides in pre and posttest $\mathrm{p}=0.001$. 
Table (6): Relationship between socio-demographic characteristics of the farming mothers and their total score of knowledge in pre and posttest program .

\begin{tabular}{|c|c|c|c|c|c|c|c|c|c|c|}
\hline \multirow{3}{*}{$\begin{array}{r}\text { Socio-demographic } \\
\text { characteristics }\end{array}$} & \multicolumn{4}{|c|}{ Pretest knowledge } & \multirow[t]{3}{*}{ P. value } & \multicolumn{4}{|c|}{ Posttest knowledge } & \multirow[t]{3}{*}{ P. value } \\
\hline & \multicolumn{2}{|c|}{$\begin{array}{r}\text { Satisfactory } \\
(\mathrm{n}=2)\end{array}$} & \multicolumn{2}{|c|}{$\begin{array}{r}\begin{array}{r}\text { Unsatisfactory } \\
(\mathrm{n}=58)\end{array} \\
\end{array}$} & & \multicolumn{2}{|c|}{$\begin{array}{r}\begin{array}{r}\text { Satisfactory } \\
(n=39)\end{array} \\
\end{array}$} & \multicolumn{2}{|c|}{$\begin{array}{r}\text { Unsatisfactory } \\
(n=21)\end{array}$} & \\
\hline & No. & $\%$ & No. & $\%$ & & No. & $\%$ & No. & $\%$ & \\
\hline \multicolumn{11}{|l|}{ Mother age: } \\
\hline$<25$ years & 0 & 0.0 & 3 & 5.2 & \multirow[t]{3}{*}{0.647} & 1 & 2.6 & 2 & 9.5 & \multirow[t]{3}{*}{0.455} \\
\hline $25-35$ years & 1 & 50.0 & 13 & 22.4 & & 10 & 25.6 & 4 & 19.0 & \\
\hline $35 \pm$ years & 1 & 50.0 & 42 & 72.4 & & 28 & 71.8 & 15 & 71.4 & \\
\hline \multicolumn{11}{|l|}{ Mother education: } \\
\hline Illiterate & 0 & 0.0 & 36 & 62.1 & \multirow[t]{4}{*}{$0.001 * *$} & 19 & 48.7 & 17 & 81.0 & \multirow[t]{4}{*}{0.100} \\
\hline Basic education & 0 & 0.0 & 15 & 25.9 & & 12 & 30.8 & 3 & 14.3 & \\
\hline Secondary & 1 & 50.0 & 6 & 10.3 & & 6 & 15.4 & 1 & 4.8 & \\
\hline University & 1 & 50.0 & 1 & 1.7 & & 2 & 5.1 & 0 & 0.0 & \\
\hline \multicolumn{11}{|l|}{ Mother occupation: } \\
\hline House wife & 0 & 0.0 & 57 & 98.3 & \multirow[t]{2}{*}{$0.001 * *$} & 36 & 92.3 & 21 & 100.0 & \multirow[t]{2}{*}{0.192} \\
\hline Worked & 2 & 100.0 & 1 & 1.7 & & 3 & 7.7 & 0 & 0.0 & \\
\hline \multicolumn{11}{|l|}{ Social class: } \\
\hline Low & 0 & 0.0 & 8 & 13.8 & \multirow[t]{3}{*}{0.073} & 4 & 10.3 & 4 & 19.0 & \multirow[t]{3}{*}{$0.012 *$} \\
\hline Middle & 0 & 0.0 & 35 & 60.3 & & 19 & 48.7 & 16 & 76.2 & \\
\hline High & 2 & 100.0 & 15 & 25.9 & & 16 & 41.0 & 1 & 4.8 & \\
\hline
\end{tabular}

Table (6): represented that, there were a statistically significant differences between mothers education, occupation and their total score of knowledge in pretest $\mathrm{P}=0.001$ and mothers social class in posttest P 0.012 .While no statistically significant differences were detected regarding the other variables in pre and posttest.

Table (7): Relationship between socio-demographic characteristics of the farming mothers' and their total score of knowledge about practice in pre and posttest program.

\begin{tabular}{|c|c|c|c|c|c|c|c|c|c|c|}
\hline \multirow{4}{*}{$\begin{array}{r}\text { Socio- } \\
\text { demographic } \\
\text { characteristics }\end{array}$} & \multicolumn{4}{|c|}{ Pretest practice } & \multirow[t]{3}{*}{ P. value } & & & \multicolumn{2}{|c|}{ Posttest practice } & \multirow[t]{2}{*}{ P. value } \\
\hline & \multicolumn{2}{|c|}{ Satisfactory } & \multicolumn{2}{|c|}{ Unsatisfactory } & & \multicolumn{2}{|c|}{ Satisfactory } & \multicolumn{2}{|c|}{ Unsatisfactory } & \\
\hline & No. & $\%$ & No. & $\%$ & & No. & $\%$ & No. & $\%$ & \\
\hline & 14 & 100.0 & 46 & 100.0 & & 47 & 100.0 & 13 & 100.0 & \\
\hline & & & & & \multicolumn{6}{|c|}{ Mother age: } \\
\hline$<25$ years & 0 & 0.0 & 3 & 6.5 & \multirow[t]{3}{*}{0.569} & 3 & 6.4 & 0 & 0.0 & \multirow[t]{3}{*}{0.639} \\
\hline $25-35$ years & 4 & 28.6 & 10 & 21.7 & & 11 & 23.4 & 3 & 23.1 & \\
\hline $35 \pm$ years & 10 & 71.4 & 33 & 71.7 & & 33 & 70.2 & 10 & 76.9 & \\
\hline & & & & & \multicolumn{6}{|c|}{ Mother education: } \\
\hline Illiterate & 7 & 50.0 & 29 & 63.0 & \multirow[t]{4}{*}{$0.013^{*}$} & 27 & 57.4 & 9 & 69.2 & \multirow[t]{4}{*}{0.400} \\
\hline Basic education & 2 & 14.3 & 13 & 28.3 & & 11 & 23.4 & 4 & 30.8 & \\
\hline Secondary & 5 & 35.7 & 2 & 4.3 & & 7 & 14.9 & 0 & 0.0 & \\
\hline University & 0 & 0.0 & 2 & 4.3 & & 2 & 4.3 & 0 & 0.0 & \\
\hline & & & & & \multicolumn{6}{|c|}{ Mother occupation: } \\
\hline House wife & 13 & 92.9 & 44 & 95.7 & \multirow[t]{2}{*}{0.674} & 44 & 93.6 & 13 & 100.0 & \multirow[t]{2}{*}{0.350} \\
\hline Worked & 1 & 7.1 & 2 & 4.3 & & 3 & 6.4 & 0 & 0.0 & \\
\hline & & & & & \multicolumn{6}{|c|}{ Social class: } \\
\hline Low & 1 & 7.1 & 7 & 15.2 & \multirow[t]{3}{*}{0.644} & 6 & 12.8 & 2 & 15.4 & \multirow[t]{3}{*}{0.504} \\
\hline Middle & 8 & 57.1 & 27 & 58.7 & & 26 & 55.3 & 9 & 69.2 & \\
\hline High & 5 & 35.7 & 12 & 26.1 & & 15 & 31.9 & 2 & 15.4 & \\
\hline
\end{tabular}

Table (7): showed that, no statistically significant differences between socio-demographic characteristics of the farming mothers' and their total score of knowledge about practice in pre and posttest except for mothers' education in pretest $\mathrm{p}=0.013$. 


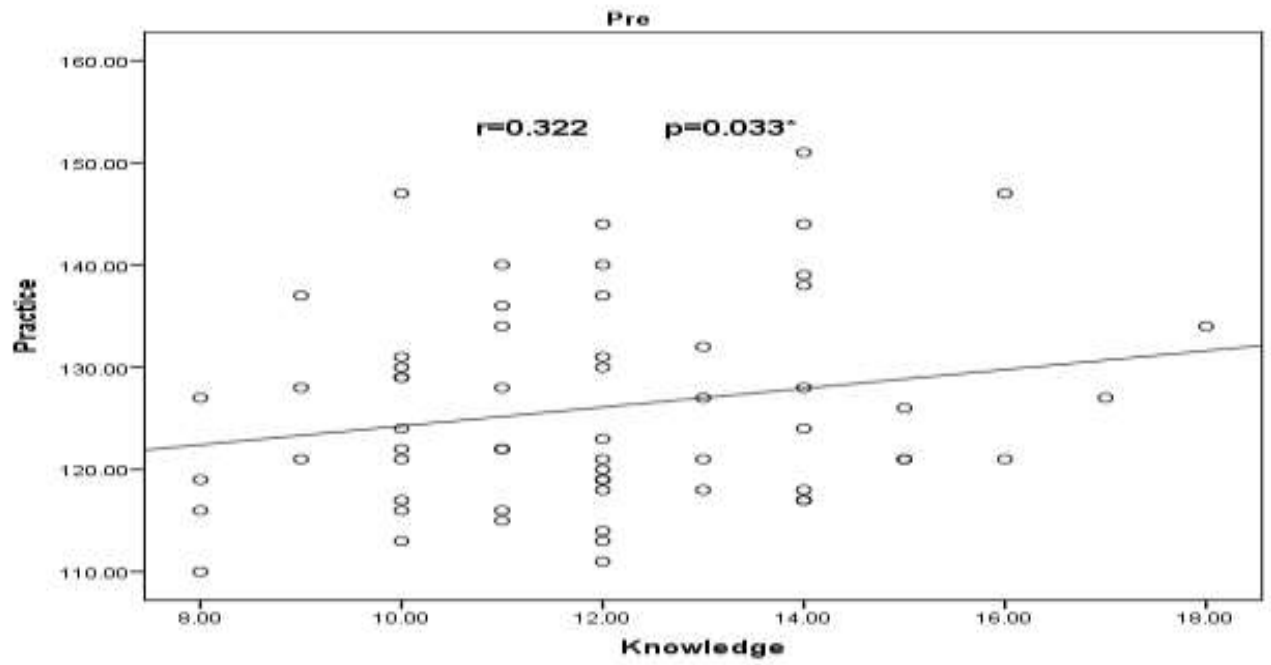

Fig (2): Correlation between total score of mother's knowledge and their total score of knowledge about practices regarding pesticides in pretest

This figure represent that ,there were a positive correlation between total score of mother's knowledge and their total score of knowledge about practices regarding pesticides in pretest, with statistically significant difference, $\mathrm{P}=0.033$, r 0.322 .

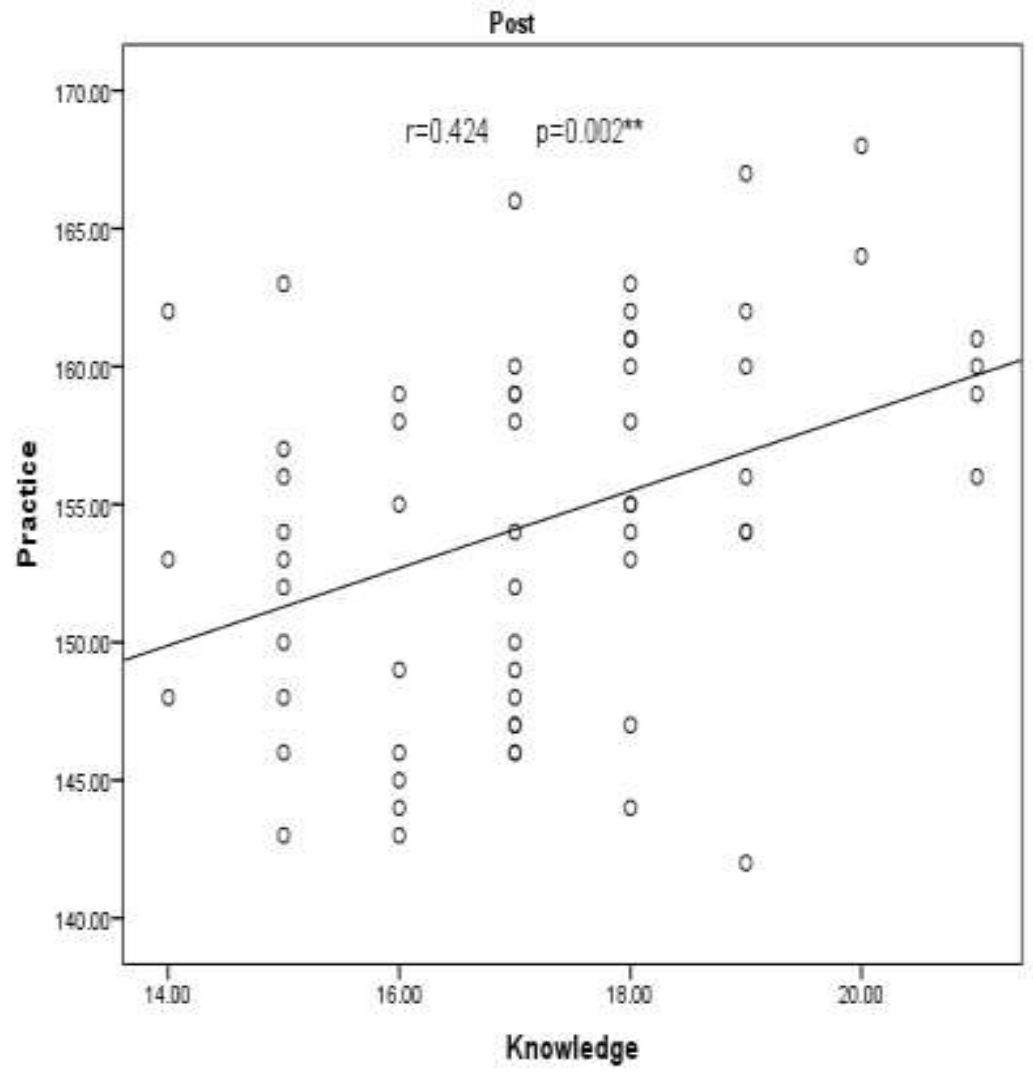

Fig (3): Correlation between total score of mother's knowledge and their total score of knowledge about practices regarding pesticides in posttest.

This figure showed that, there were a positive correlation between total score of mother's knowledge and their total score of knowledge about practices regarding pesticides in posttest, and statistically significant difference were detected, $\mathrm{P}=0.002$, r 0.424 . 


\section{Discussion}

One of the major problems facing the world today is environmental pollution. The source of the pollution in the area of agriculture is excessive use of pesticide [18]. Pesticide exposure has been linked with immediate and delayed health effects. Not only farmworkers exposed to pesticides while working in the fields, they and their families may also face increased pesticide exposure due to living in proximity to where the pesticides are applied. Children and infants can be particularly affected by pesticides because of their physiological immaturity and greater risk of exposure to pesticides[19].

Concerning the mothers' age, the current study showed that, less than three quarters were 35 years and more and the mean age 38.8 \pm 9.7 . The results of the present study in the same line with [20], who reported that (51\%) of the studied sample were age ranged from 30-49 years. Also the results agree with [21], who found that mean age of participants was 41.8 years.

Regarding the mothers' education, the present study found that, less than two thirds of farming mothers were illiterate .This result disagree with [5], who found that, more than half of study participant were graduated from secondary school or higher. Our results in accordance with [22], who reported that, the majority of the studied sample (84\%) was completed high school. Also the results inconsistence with [23], who indicated that around half $(45.5 \%)$ of the study participants were illiterate.

The present study showed that ,the vast majority of farming mothers were house wife and farmer and not received training about pesticide. The present study disagree with [24], who represent that 40 percent of mothers were employed in farm work, but not received pesticide training. Regards to social class more than half of the farming mothers had middle social class. This in agreement with [22], who reported that, the majority of participants (84\%) were high social class. As regards marital status, the present study showed that, two third of the mothers were widow. These finding in accordance with [25], who conducted a study in Cairo University and found that the majority of the study participant were married.

Concerning to the number of children who exposed to poisoning by pesticides $13.3 \%$ exposed to poisoning only once. These findings inconsistence with [26], who found that $63.5 \%$ and $76.4 \%$ of the poisoned respondents reported two or more poisonings.

Regarding the frequency of using pesticides inside the home, the present study found that, more than three quarter of the mothers using pesticides every four days and more weekly. These results incongruent with [5], who reported that most of the families (80.5\%) frequently applied pesticides (4-7 days/week). Also the results of the present study in accordance with [20], who reported that (97\%) of farmer hadn't use pesticides.

As regards to child complain the results found that one quarter complain from gastrointestinal disturbance, these results disagree with [27], who reported that pesticides were the most common causes of poisoning and $60 \%$ of poisoned children had complain from gastrointestinal disturbance.

As regards the farming mothers' knowledge about pesticides in pre and post program application, it was observed that mothers' knowledge were improved after the program application. This result implies the importance of an educational program to raising the mother's awareness about pesticides. This result in the same line with [17], who mentioned that continuous educational program increases the knowledge of participants.

The present study revealed that the mothers said there were different methods for pesticide to invade of the human body as inhalation, eyes, skin and ingestion.The results similar to the finding of [28], who found that the farming mothers and their children may be exposed to pesticides in various ways.

Regarding mothers' knowledge about effect of pesticides on children's health, the present study found that, the farming mothers said the exposure to pesticides causing sensitivity of the chest and skin, effect on the liver, child memory ,child intelligence and nervous system. These results agree with [29], who reported that $(92.0 \%)$ of sample think pesticides can have a negative effect on the health. While the results in accordance with [30], who found that majority of the participant reported that exposure to pesticides hadn't an adverse effect on human health.

Concerning the mothers' knowledge about practice precaution before, during, after and in storing pesticides at home. Most of the mothers' had unsatisfactory knowledge about practice in pretest, while there was improvement in their knowledge about practice after program application. This result implies the importance of an educational program to rising the mother's awareness about pesticides .

Another focus of this study was to examine the mothers' knowledge about practice regarding using protective methods during use of pesticides; it was found that, less than half of the mothers after program application still not used the personnel protective equipment. This can explained by unavailability or high cost of personnel protective equipment, lack the farming mothers' knowledge about types and importance of using the personnel protective equipment and may be related to their habits and belief. This result disagree with [31], who reported that the majority of participants didn't use appropriate personnel protective equipment when handling pesticides and (67\%) use ordinary clothing when spraying. Also these finding in accordance with [26], who reported that $(66.9 \%)$ of farmers no personnel protective equipment use at all. 
The results indicated that, there were improvement in the total score of the farming mothers' knowledge and their knowledge about practice in posttest. The results in the same line with [5], who found that knowledge scores of participants improved after health education program, as compared to the pre-program. Although the practice scores were improved. The findings disagree with [32], showed that the knowledge of the respondents to the use of pesticides is still need to be improved.

The present study revealed that, the illiterate mothers showed greater improvement in their knowledge and their knowledge about practice than mothers with secondary school and university degree. These results disagree with [5], who found that the parents with high school or university degree showed significantly greater improvements in knowledge and practice than parents who were illiterate or only able to read and write. Also the results inconsistence with [26], reported that there was a significant association between respondents' education (High education versus low education) and reported practice toward pesticide use

The present study indicated that, there were a positive correlation between mothers' total score of knowledge and their total score of knowledge about practice regarding pesticides. With statistically significant difference. These results agreement with [24], who found that there is a significant correlation $(r=0.525 ; p<$ 0.001 ) between the knowledge score and the practice score regarding pesticides. While our results disagree with the finding of [33], who found that the improvement of knowledge scores was significantly higher than that of practice scores.

\section{Conclusions}

Most of farming mothers had poor level of knowledge and unsatisfactory knowledge about practice regarding pesticide in preprogram and after implementation of the program, the level of mothers' knowledge and their knowledge about practice improved.

\section{Recommendations}

- Medical conveys in the village for the public about pesticides by the directors of rural health units shared with professors in medicine, nursing in the university and association of agriculture.

- Using mass media to disseminate correct information about pesticides and to increasing the mothers' awareness about its harmful effect on health.

- Certain efforts must be placed on the execution of personal protective measures which necessary to decrease the pesticide exposure of mothers and their children.

\section{References}

[1]. C. Ramesh \& Gupta, Toxicology of Organophosphate \& Carbamate Compounds. Academic Press,2011,pp. 352-353. ISBN 978-008-054310-9.

[2]. R. Gilden, K Huffling \& B Sattler, Pesticides and health risks. J Obstet Gynecol Neonatal Nurs 39 (1)2010:10310. doi:10.1111/j.1552-6909.2009.01092.x. PMID 20409108

[3]. E. Cha, Y Ho Khang \& W Lee, Mortality from and Incidence of Pesticide Poisoning in South Korea: Findings from National Death and Health Utilization Data between 2006 and 2010, J PLoS One. 2014; 9(4): e 95299.

[4]. R. Langley \& S Mort, Human exposures to pesticides in the United States. J Agromedicine, 17,2012,300-315.

[5]. T. Farahat, F Farahat \& A Michael, Eastern Mediterranean Health Journal, 15, (1), 2009.

[6]. J. Beitz, Integrating Environmental Health Into Nurse Practitioner Training-Childhood Pesticide Exposure Risk Assessment, Prevention, and Management. AAOHN J. Author manuscript; available in PMC 2013 Aug 9. Published in final edited form as: AAOHN J. 2010 Aug; 58(8): 349-355. doi: 10.3928/08910162-20100728-02

[7]. O. Nesheim, M. Frederick, Fisheln \& M Mossler, Toxicity of Pesticides one of a series of the Pesticide Information Office, Food Science and Human Nutrition Department, Florida Cooperative Extension Service, Institute of Food and Agricultural Sciences, University of Florida, 2011,pp I-13.

[8]. P. Data, Pediatric Nursing. third edition, London, Philadelephia, panama, 2014,pp168-170.

[9]. J. Liu, Pesticide Exposure and Child Neurodevelopment Workplace Health Saf. Author manuscript; available in PMC 2014 Nov 28.Published in final edited form as: Workplace Health Saf. 2012 May; 60(5), 2014, 235-243. doi: 10.3928/21650799-2012042673

[10]. M. Huckleberry \& D Wilson, Wong's Nursing Care of the infants and children. $10^{\text {th }}$ ed., Philadelphia, St. Louis, Mosby Company, 2015, pp 544-556.

[11]. L. London, C Beseler, M Bouchard, D Bellinger, \& C Colosio, Neurobehavioral and neurodevelopmental effects of pesticide exposures. Neurotoxicology 33, 2012, 887-896.

[12]. H. Kim, E Cha, Y Ko, J Kim \& S Kim, Pesticide poisonings in South Korea: findings from the National Hospital Discharge Survey 2004-2006. Hum Exp Toxicol 31,2012,751-758 [PubMed].

[13]. 13.world Health Organization (WHO) (2009): The WHO Recommended Classification of Pesticides by Hazard and Guidelines to Classification. International Programme on Chemical Safety; Geneva, Switzerland.

[14]. H. Rother, R Hall \& L London, Pesticide Use Among Emerging Farmers In South Africa: Contributing Factors And Stakeholder Perceptions. Development Southern [ Africa, 25(4), 2009, 399-424.

[15]. A. Abd El-Twaab, Assessment of social class scale: Assiut University, Faculty of education, department of psychology ,2004

[16]. S. Khalaf, knowledge, attitude and practice of mother about chicken pox. Thesis submitted for partial fulfillment of requirements for Master Degree in Community Health Nursing. Faculty of nursing in Assiut, 2009, P73.

[17]. G. Sherwood, Nurse administration's perception of the impact of continuing nursing education in underserved areas. J Cont Educ Nurse, 1996,27 (3): 129-33 
[18]. R. Elmore, \& T Arcury, Pesticide exposures beliefs among Lation Farm workers In North Calonia's Tree Industry, Amaercan Journal of industrialmedicine, 2010, vol, 40, No (2), pp : 153-160.

[19]. P. Rao, S Quandt, A Doran, B Snively, T Arcury, Pesticides in the homes of farmworkers: Latino mothers' perceptions of risk to their children's health.Health Educ Behav. 2007, Jun;34(3):551.

[20]. S. Naidoo, L London, H Burdorf, R Naidoo \& H Kromhout, Pesticide safety training and practices in women working in smallscale agriculture in South Africa. Occup Environ Med. 2010, Dec; 67(12):823-8.

[21]. A. Oesterlund, J Thomsen, D Sekimpi, J Maziina, A Racheal \& E Jørs, Pesticide knowledge, practice and attitude and how it affects the health of small-scale farmers in Uganda: a cross-sectional study, Afr Health Sci. 2014, Jun; 14(2): 420-433.

[22]. P.Beamer, Pesticide Exposure of Farmworkers' Children, Pesticides in the Modern World -Effects of Pesticides Exposure, Dr. Margarita Stoytcheva (Ed.) 2011, ISBN: 978-953-307-454-2, InTech, Available from: http://www.intechopen.com/books/pesticides-in-the-modern-world-effects-of-pesticidesexposure/pesticide-exposure-offarmworkers-children.

[23]. O. Abd Elzaher, M Qayed, S Mohamed \& A Mohamed, Farmar Knowledage , Attitude and practice about Health Hazards of pesticides use in a village at Abnoub District. Assiut Governorate. Faculty of Nursing Assiut Uviversty, Egypt, 2014.

[24]. P. Kumari \& K Reddy, Knowledge and Practices of safety use of Pesticides among Farm workers IOSR Journal of Agriculture and Veterinary Science (IOSR-JAVS)e-ISSN: 2319-2380, p-ISSN: 2319-2372. 2013,Volume 6, Issue 2 (Nov. - Dec., PP 01-08.

[25]. E. Mo'awad, Farmar Awareness about health hazards of agricultural Pesticide use at shubrant village, Giza Governorate, Faculty of Nursing Cario Uviversty, Egypt, 2006, pp.1-27.

[26]. E .Lekei, A Ngowi, \& L London 2014Farmers' knowledge, practices and injuries associated with pesticide exposure in rural farming villages in Tanzania BMC Public Health.; 14: 389. Published online 2014 Apr 23. doi: 10.1186/1471-2458-14-389

[27]. A. Basheir. Hassan1 \&Mohamed G. Siam2, Patterns of Acute Poisoning in Childhood in Zagazig, Egypt: An Epidemiological Study. Received 23 May 2014; Revised 29 August 2014; Accepted 11 September 2014; Published 29 October 2014. Academic Editor: Barbara Polivka

[28]. P. Panuwet, W Siriwong, T Prapamontol, B Ryan, N Fiedler, Mark. G Robson \& D Barr, Agricultural Pesticide Management in Thailand: Situation and Population Health Risk, Environ Sci Policy. 2013, 17: 72-81.

[29]. H. Jensen, F Konradsen, E Joers, J Petersen, \& A Dalsgaard, Pesticide Use and Self-Reported Symptoms of Acute Pesticide Poisoning among Aquatic Farmers in Phnom Penh, Cambodia. Journal of Toxicology. 2011, Article ID 639814.

[30]. M. Yassin, J Abu Mourad \& M Safi, Knowledage, Attitude, practice and toxicity symptoms associated with pesticides use among farm workers in Giza Strip. Occuptional and environmental Medicine, 2012,pp.387-394.

[31]. L, Beamer, who study Pesticide Exposure of Farmworkers' Children and found that Wears protective, 2013.

[32]. K. Assis, J Eco. I Res, Knowledge, Attitude and Practices of Farmers To wards Organic Farming 2(3), 1-6 ISSN: 2229-6158 IJER | MAY - JUNE 2011 Available online@www.ijeronline.com 1.

[33]. S. Norkaew, W Siriwong, S Siripattanakul \& M Robson, Knowledge, Attitude, and Practice (KAP) of Using Personal Protective Equipment (PPE) for Chilli-Growing Farmers in Huarua Sub-District, Mueang District, Ubonrachathani Province, Thailand. Journal of Heath Research. 2010, 24(2):83-86. 